University of Nebraska - Lincoln

DigitalCommons@University of Nebraska - Lincoln

\title{
Physical, Rheological, Functional, and Film Properties of a Novel Emulsifier: Frost Grape Polysaccharide from Vitis riparia Michx
}

\author{
William T. Hay \\ USDA-ARS, Will.Hay@ars.usda.gov \\ Steven F. Vaugh \\ USDA-ARS, Steven.Vaughn@ars.usda.gov \\ Jeffrey A. Byars \\ USDA-ARS, Jeffrey.Byars@ars.usda.gov \\ Gordon W. Selling \\ USDA-ARS, Gordon.Selling@ars.usda.gov \\ Derek M. Holthaus \\ TIC Gums Inc.
}

See next page for additional authors

Follow this and additional works at: https://digitalcommons.unl.edu/usdaarsfacpub

Hay, William T.; Vaugh, Steven F.; Byars, Jeffrey A.; Selling, Gordon W.; Holthaus, Derek M.; and Price, Neil P.J., "Physical, Rheological, Functional, and Film Properties of a Novel Emulsifier: Frost Grape Polysaccharide from Vitis riparia Michx" (2017). Publications from USDA-ARS / UNL Faculty. 1803. https://digitalcommons.unl.edu/usdaarsfacpub/1803

This Article is brought to you for free and open access by the U.S. Department of Agriculture: Agricultural Research Service, Lincoln, Nebraska at DigitalCommons@University of Nebraska - Lincoln. It has been accepted for inclusion in Publications from USDA-ARS / UNL Faculty by an authorized administrator of DigitalCommons@University of Nebraska - Lincoln. 


\section{Authors}

William T. Hay, Steven F. Vaugh, Jeffrey A. Byars, Gordon W. Selling, Derek M. Holthaus, and Neil P.J. Price 


\title{
Physical, Rheological, Functional, and Film Properties of a Novel Emulsifier: Frost Grape Polysaccharide from Vitis riparia Michx
}

\author{
William T. Hay, ${ }^{\dagger}$ Steven F. Vaughn, ${ }^{\ddagger}$ Jeffrey A. Byars, ${ }^{\ddagger}$ Gordon W. Selling, ${ }^{\dagger}$ Derek M. Holthaus, $"$
} and Neil P. J. Price ${ }^{*, \S}$

${ }^{\dagger}$ Plant Polymer Research Unit, USDA, Agricultural Research Service, National Center for Agricultural Utilization Research, 1815
North University Street, Peoria, Illinois 61604, United States
${ }^{\ddagger}$ Functional Foods Research Unit, USDA, Agricultural Research Service, National Center for Agricultural Utilization Research, 1815
North University Street, Peoria, Illinois 61604, United States
${ }^{\S}$ Renewable Product Technology Unit, USDA, Agricultural Research Service, National Center for Agricultural Utilization Research,
1815 North University Street, Peoria, Illinois 61604, United States

${ }$ TIC Gums Inc., 10552 Philadelphia Road, White Marsh, Maryland 21162, United States

ABSTRACT: A novel emulsifier, Frost grape polysaccharide (FGP), isolated from natural exudate of the species Vitis riparia Michx, was physically and rheologically characterized. The determination of the physical, structural, thermodynamic, emulsification, film, and rheological properties of FGP provide essential details for the commercial adoption of this novel plant polysaccharide. FGP is capable of producing exceptionally stable emulsions when compared with the industrially ubiquitous gum arabic (GA). The FGP isolate contained a negligible amount of nitrogen (0.03\%), indicating that it does not contain an associated glycoprotein, unlike GA. Solutions of FGP have a high degree of thermostability, displaying no loss in viscosity with temperature cycling and no thermal degradation when held at $90{ }^{\circ} \mathrm{C}$. FGP is an excellent film former, producing high tensile strength films which remain intact at temperatures up to $200{ }^{\circ} \mathrm{C}$. This work identified a number of potential food and pharmaceutical applications where FGP is significantly superior to GA.

KEYWORDS: frost grape polysaccharide, gum arabic, Vitis riparia, rheology, emulsifier

\section{INTRODUCTION}

Plant polysaccharides are utilized in a wide variety of commercial applications including food and paper industries and even for hydraulic fracking. ${ }^{1}$ Of particular importance in the food industry are arabinogalactans (AG), structurally complex branched polysaccharides predominantly consisting of arabinose and galactose residues. ${ }^{2}$ These include gum arabic (GA) and gum ghatti and find uses as emulsifiers and thickening agents for a variety of food applications. GA is a wound polysaccharide harvested from trunks and branches of acacia trees and is used in aqueous solutions as a low-viscosity emulsifier. The quality, availability, and price of GA vary considerably, ${ }^{3,4}$ and it is therefore desirable to have a domestic substitute of consistent quality. The recently identified frost grape polysaccharide (FGP), from a native North American grapevine species, may be a potential replacement for $\mathrm{GA}^{5}$ Frost grape (Vitis riparia Michx.) vines are cold tolerant and resistant to grape phylloxera, a serious insect pest of wine grapes. Because of this resistance it is used extensively as grafted rootstock for edible grapes (Vitis vinifera L.). ${ }^{6,7}$

Similar to GA, FGP is a complex polysaccharide with a readily recognizable monosaccharide profile comprised of arabinose (Ara), galactose (Gal), xylose (Xyl), mannose (Man), and glucuronic acid (GlcA) that readily distinguishes it from other $\mathrm{AG}^{5}{ }^{5}$ The major structural component of FGP is a carbohydrate backbone composed of L-arabinofuranose (L-Araf, $55.2 \%$ ) and D-galactopyranose (D-Galp 30.1\%), with smaller components of D-xylose (11.2\%) and D-mannose (3.5\%). The $\beta$ Gal $p$ and three $\alpha$ Araf groups form a Araf- $\alpha 1$,3-Araf- $\alpha 1,2$-Araf$\alpha 1,2-$ Gal $p$ structural motif, with complex branching composed of the Xyl, Man, and D-glucuronic acid residues. Preliminary rheological research demonstrated that FGP forms highly viscous aqueous solutions at $1-2 \% \mathrm{w} / \mathrm{v}$. At these concentrations, FGP provided stable emulsions with flavoring oils. ${ }^{5}$ The FGP has an overall molecular weight of 1-10 MDa and, unlike GA, does not contain an antigenic hydroxyproline-rich protein. GA contains an associated protein which is covalently linked to the carbohydrate through serine and hydroxyproline resides, and the protein concentration and resulting emulsifying properties can vary widely. ${ }^{8,9}$ Generally higher protein content in GA is correlated with positive emulsion characteristics, though this relationship is not always accurate and low protein GA samples have been found to possess excellent emulsifying characteristics. ${ }^{10}$ For GA, large gum to oil ratios (greater than $1: 1)$ are typically utilized to generate stable emulsions. ${ }^{11}$

As emulsifiers, polysaccharides are characterized as hydrophilic polymers having high molecular weight but lacking significant surface activity. This is starkly different from smallmolecular surfactants, like lecithin and polysorbates, which are typically very surface active but lack long-term emulsion stability. ${ }^{4}$ An emulsifying agent must have some surface activity,

Received: July 18, 2017

Revised: $\quad$ September 8, 2017

Accepted: September 12, 2017

Published: September 13, 2017 
by lowering the interfacial tension between the oil and water interface. ${ }^{12}$ Most gums contain hydrophobic proteins or protein fragments, which can strongly absorb at the liquid interface, lowering interfacial tension. Some gums have been reported to possess little protein material but have excellent emulsification characteristics, such as corn fiber gum. ${ }^{13}$ For GA, nitrogen content is highly correlated with surface activity, and in general the higher the \% nitrogen of GA, the more surface active the sample. ${ }^{14}$ However, Dickenson et al. observed that very low \% nitrogen GA samples $(0.09 \% \mathrm{~N})$ contained enough proteinaceous fragments to produce stable emulsions with a very fine oil droplet size. ${ }^{15}$ Increasing the protein concentration to approximately $1 \% \mathrm{~N}$ caused the droplet size to become highly course, and the resulting emulsions were unstable until the nitrogen concentration was above $1 \%{ }^{9}$ A stable emulsion depends on preventing the aggregation or coalescing of micelles through steric stabilization, and high molecular weight hydrophilic polymers provide an excellent thick steric stabilizing layer. $^{12,15}$

Plant exudates are a renewable product which are widely utilized for food coatings to preserve the food product and can improve texture and mouthfeel. ${ }^{16-18}$ In emulsions, GA increases the viscosity of solutions and produces a thick and creamy mouthfeel as the emulsion droplets act as filler particles. ${ }^{19}$ As film coatings GA can be utilized to polish confectionaries, such as chocolate, or as fruit coatings on apples to improve flavor and textural qualities throughout storage. ${ }^{20,21}$ Determining the physical, rheological, functional, and film properties of FGP may help elucidate possible end uses of this novel plant exudate.

The objectives of this investigation were to (1) further define the physical and structural characteristics of FGP, (2) quantify the emulsification properties of FGP as compared with GA, and (3) determine the physical and rheological properties of solutions and films prepared from FGP. By accomplishing these objectives, the overall value and processing parameters of FGP will be better understood.

\section{MATERIALS AND METHODS}

2.1. Materials. The frost grape polysaccharide (FGP) was extracted according to the method listed below. A commercial grade $\mathrm{GA}^{22}$ (G9752; GA), glycerol and sodium dodecyl sulfate (SDS) were purchased from Sigma (St. Louis, MO). Deionized water was used for the preparation of all solutions.

2.2. Extraction of Frost Grape Polysaccharide from Frost Grape. The frost grape polysaccharide (FGP) was obtained from 5 to 7 year-old debarked stems (3.5-6.0 cm in diameter) growing in Peoria County, IL, and harvested in October, 2015. The debarked stems were then chipped in a commercial wood chipper (Patriot Chipper Shredder Vac, model CSV-2515, Patriot Products, Inc., Pewaukee, WI), and further ground into sawdust using a Fritsch cutting mill (Fritsch $\mathrm{GmbH}$, Idar-Oberstein, Germany) fitted with a $4 \mathrm{~mm}$ screen. The sawdust was extracted with boiling deionized water to obtain a viscous, tan-colored extract. The FGP was purified from the extract by precipitation with 1:1 volumes of extract/ethanol $(95 \% \mathrm{v} / \mathrm{v})$. The precipitate was further washed with three ethanol rinses in a vacuum funnel, and the precipitate was dried in a drying oven at $40{ }^{\circ} \mathrm{C}$. The dried precipitate was redissolved in $500 \mathrm{~mL}$ of boiling deionized water until it was completely solubilized. The FGP solution was frozen at $-80{ }^{\circ} \mathrm{C}$ and then subsequently lyophilized for $48 \mathrm{~h}$ to obtain the FGP.

2.3. X-ray Diffraction. X-ray diffraction spectra analyses were performed using a Bruker D2 Phaser (Bruker AXS Inc., Billerica, MA) $\mathrm{X}$-ray diffractometer. The $\mathrm{X}$-ray source was $\mathrm{Cu}-\mathrm{K} \alpha$ radiation at a current of $10 \mathrm{~mA}$ and $30 \mathrm{kV}$, set up using $\theta / \theta$ geometry. Samples were scanned at $5-30^{\circ}, 2 \theta$, step size $0.01^{\circ}, 0.2 \mathrm{~s} / \mathrm{step}$, and stage rotation 10 $\mathrm{rpm}$. Initial divergence slit size was $0.6 \mathrm{~mm}$ and a $1 \mathrm{~mm}$ air scatter screen was used above the sample. A Lynxeye detector was used with a $2.5^{\circ}$ Soller slit and a $\mathrm{Ni}-\mathrm{K} \beta$ filter.

2.4. Fourier Transform-Infrared Spectroscopy and NMR Analysis. Infrared spectra were obtained on a Frontier attenuated total reflectance (ATR)-Fourier transforminfrared spectrometer (PerkinElmer, Waltham, MA) fitted with a diamond ATR crystal. A background scan was performed under ambient atmosphere, and the data analysis and baseline correction were performed automatically by the operating software. Films were placed directly on the crystal. The FT-IR spectra were obtained from 650 to $4000 \mathrm{~cm}^{-1}$ at a spectral resolution of $4 \mathrm{~cm}^{-1}$. All NMR experiments were performed on a variable temperature Avance spectrometer (Bruker Biospin, Billerica, MA) operating at $500.11 \mathrm{MHz}$ using a standard $5 \mathrm{~mm}$ z-gradient BBI probe at $90{ }^{\circ} \mathrm{C}$. The deuterated solvents used were obtained from Cambridge Isotope Laboratories (Tewksbury, MA).

2.5. Differential Scanning Calorimetry and Thermal Gravimetric Analysis. The thermal properties of the samples were studied using differential scanning calorimetry (DSC) using a Q2000 MDSC (TA Instruments, New Castle, DE) and thermal gravimetric analysis (TGA) using a Q500 Modulated TGA (TA Instruments, New Castle, $\mathrm{DE})$. For DSC, each sample $(\sim 5 \mathrm{mg})$ was weighed into a tared aluminum DSC pan, which was then hermetically sealed and heated in a nitrogen atmosphere from -60 to $190{ }^{\circ} \mathrm{C}$ at a heating rate of $10{ }^{\circ} \mathrm{C} /$ min, then cooled back to $-60{ }^{\circ} \mathrm{C}$ at the same rate followed by a second heating cycle using the same conditions. For TGA, samples $(\sim 10 \mathrm{mg})$ were weighed into an open platinum TGA pan and heated from room temperature to $800{ }^{\circ} \mathrm{C}$ at a heating rate of $10{ }^{\circ} \mathrm{C} / \mathrm{min}$ in a nitrogen atmosphere. DSC and TGA data were analyzed using TA Instruments' Universal Analysis software.

2.6. Water Vapor Absorption/Desorption. Water sorption analysis was performed on the FGP using a TA Instruments Q5000SA dynamic vapor sorption analyzer (TA Instruments, New Castle, DE). Sample absorption/desorption was determined in a $25{ }^{\circ} \mathrm{C}$ nitrogen atmosphere through gravimetric measurements of mass change as moisture content of the sample increased or decreased on exposure to various relative humidities. Humidity was changed by $10 \%$ after 180 min at each step, stepwise from 0 to $90-0 \%$ humidity. If the sample weight change was less than $0.05 \%$ of the sample weight for $10 \mathrm{~min}$ at a given humidity, then the humidity would be automatically changed to the next step.

2.7. Percent CHN Analysis. $\mathrm{CHN}$ analysis was performed using a PerkinElmer 2400 series II Dumas-type elemental analyzer (PerkinElmer, Waltham, MA) using approximately 3-4 mg of FGP. Calibration was performed using an acetanilide standard (PerkinElmer PN 0240-1121).

2.8. Preparation of Sample Solutions. Solutions of FGP and GA, approximately $\mathrm{pH} 5$ and 4.5, respectively, were prepared by dispersing the solid powders in deionized water and then continuously stirring with a magnetic stir bar at $25{ }^{\circ} \mathrm{C}$ for $24 \mathrm{~h}$.

2.9. Emulsifying Activity Index and Emulsion Stability Index. Emulsifying activity index (EAI) and emulsion stability index (ESI) are useful in determining emulsion characteristics and were calculated according to the method outlined by Wu et al. ${ }^{23}$ Solutions of FGP and GA were prepared at $0.1 \%$ solids solutions $(1 \mathrm{mg} / \mathrm{mL})$ according to the procedure in 2.8. Solutions were centrifuged at $4000 \mathrm{~g}$ for $20 \mathrm{~min}$ using a Sorvall Legend XFR centrifuge (Thermo Scientific, Waltham, $\mathrm{MA}$ ). Supernatant was isolated, and $6 \mathrm{~mL}$ was transferred to a beaker containing $2 \mathrm{~mL}$ of corn oil and the mixture was homogenized for 1 min at $20000 \mathrm{rpm}$ using a Power Gen 35 hand-held micro homogenizer (Fisher Scientific, Pittsburgh, PA). Immediately after homogenization, a $50 \mu \mathrm{L}$ aliquot of the homogenized solution was added to $5 \mathrm{~mL}$ of $0.1 \%$ SDS, to prevent any flocculation or adherence to the sides of the cuvette, and the light absorbance of the solution was measured at $500 \mathrm{~nm}$ using a background of $0.1 \%$ SDS with a UV-2600, UV-vis spectrometer (Shimadzu, Kyoto, Japan). After $10 \mathrm{~min}$ an additional $50 \mu \mathrm{L}$ aliquot was treated in the same fashion and the light absorbance of the solution is measured as above. The procedure was repeated in triplicate. The EAI was calculated: EAI $\left(\mathrm{m}^{2} / \mathrm{g}\right)=2 T\left(A_{0} \times\right.$ dilution $/ C \times \Phi \times 10000)$, where $T=2.303 ; A_{0}=$ absorbance 


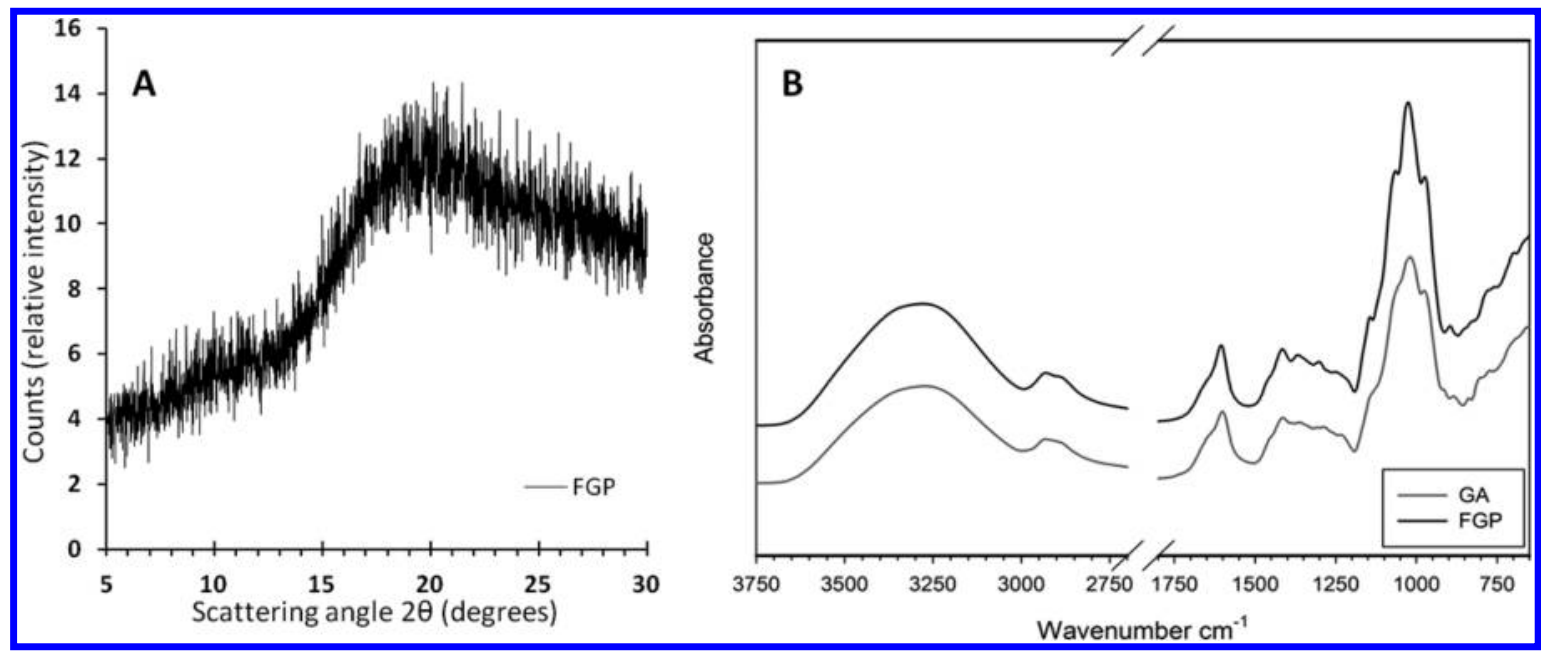

Figure 1. (A) Representative X-ray scattering pattern of FGP and (B) infrared spectrum of FGP determined using ATR FT-IR.

measured immediately after homogenization; dilution $=100, C=$ mass of emulsifier/unit volume $(\mathrm{g} / \mathrm{mL})$ of aqueous phase prior to emulsion formation, and $\Phi$ is the oil volume fraction of the emulsion. The ESI was calculated: ESI $(\mathrm{min})=A_{0} \times \Delta t / \Delta A$, where $\Delta t=10 \mathrm{~min}$ and $\Delta A$ is the change in absorbance from $A_{0}$ to $A_{10}$, absorbance measured at 10 $\min ^{23}$

2.10. Flow Property Measurements. Measurements in controlled shear rate flow to determine solution viscosity were conducted on an ARES LS1 (TA Instruments, New Castle, DE) fluids rheometer equipped with a $50 \mathrm{~mm}$ diameter parallel plate geometry with a Peltier plate to maintain temperature at $25.0 \pm 0.1{ }^{\circ} \mathrm{C}$. Small amplitude oscillatory shear flow measurements of the storage modulus $G^{\prime}$ and loss modulus $G^{\prime \prime}$ were also measured in the linear viscoelastic region as determined by a strain sweep. Humidity covers were used to prevent drying of the samples. All samples were tested in triplicate. Measurements to determine solution response to temperature cycling were performed using an AR2000 (TA Instruments, New Castle, DE) fluids rheometer with a double walled concentric cylinder geometry equipped with a Peltier heater and humidity covers. Sample solutions were heated from 20 to $90{ }^{\circ} \mathrm{C}$ and back to $20{ }^{\circ} \mathrm{C}$, at a rate of $2.00{ }^{\circ} \mathrm{C}$ per minute and a shear rate of $100 \mathrm{~s}^{-1}$ for two continuous heating and cooling cycles. Measurements in controlled shear rate flow to determine fresh emulsion viscosity (as prepared in 2.9) were performed in triplicate using an AR2000 (TA Instruments, New Castle, DE) fluids rheometer with a double walled concentric cylinder geometry equipped with a Peltier heater set to maintain at $25.0 \pm 0.1$ ${ }^{\circ} \mathrm{C}$. The intrinsic viscosity, $[\eta]$, in water at $25{ }^{\circ} \mathrm{C}$ was measured using a Schott AVS 360 automated viscosity system (Hofheim, Germany). The intrinsic viscosity was calculated as the average of the value extrapolated to zero concentration, $C$, of $\ln \left(\eta_{\mathrm{rel}}\right) / C$ and $\eta_{\mathrm{sp}} / C$, where the relative viscosity $\eta_{\text {rel }}=\eta / \eta_{\mathrm{s}}$, the specific viscosity $\eta_{\mathrm{sp}}=\eta_{\mathrm{rel}}-1, \eta$ is the solution viscosity, and $\eta_{\mathrm{s}}$ is the solvent viscosity.

2.11. Film Preparation and Physical Property Determination. FGP and GA films were produced by preparing solutions (2.8) to a final solids concentration was $2 \%$ by weight. Glycerol was added to each solution so that the final concentration of glycerol was $20 \%$ based on the total solids. Solutions were degassed using a vacuum to remove entrapped air, and solutions were then poured into a $12 \mathrm{~cm} \times$ $18 \mathrm{~cm} \times 0.4 \mathrm{~cm}$ silicon rubber gasket placed onto a glass plate coated with BYTAC nonstick adhesive film (Saint Gobain Performance Plastics, Poestenkil, NJ). The solutions were allowed to air-dry over the course of $96 \mathrm{~h}$ at room temperature. Physical property samples were equilibrated for 1 week at $50 \%$ relative humidity and $23{ }^{\circ} \mathrm{C}$ prior to testing. Tensile strength, Young's modulus, and \% elongation were obtained using an Instron Universal Testing Machine, model 4201 (Canton, MA) according to the ASTM D638 Type V testing procedure (crosshead speed $10 \mathrm{~mm} / \mathrm{min}$, gauge length $7.62 \mathrm{~mm}$, load cell $100 \mathrm{~N}$ ). Rectangular test strips with dimensions of $20 \mathrm{~mm}$ long, $6.3 \mathrm{~mm}$ wide, and $0.05 \mathrm{~mm}$ thick were cut from the air-dried films and evaluated using dynamic mechanical analysis (DMA). Storage modulus $\left(G^{\prime}\right)$, loss modulus $\left(G^{\prime \prime}\right)$, loss tangent $(\tan \delta)$, and change in length of the film $(\Delta L)$ were measured with an ARES G2 controlled strain rheometer (TA Instruments, New Castle, DE) equipped with a rectangular tension geometry. Measurements of $G^{\prime}, G^{\prime \prime}$, and $\tan \delta$ were conducted at a frequency of $1.0 \mathrm{rad} / \mathrm{s}$ and a strain of $0.05 \%$. Each sample was heated from -70 to $200{ }^{\circ} \mathrm{C}$ with a forced air oven at a rate of $5^{\circ} \mathrm{C} / \mathrm{min}$.

2.12. Statistical Analysis. Results for tensile strength, Young's modulus, \% elongation, toughness, emulsion activity index, and emulsion stability index were evaluated by analysis of variance and treatment means were separated by the Tukey adjusted least significant difference at $\alpha=0.05$, performed in Proc Mixed SAS v9.4 (SAS Institute Inc., Cary, NC). Regression equations for the solution viscosity shear rate response were determined using Excel 2007 (Microsoft, Redmond, WA).

\section{RESULTS AND DISCUSSION}

3.1. Characterization. From the X-ray diffraction analysis there is no indication of crystallinity in FGP, but rather the large polysaccharide forms an amorphous structure (Figure 1A). The ATR FT-IR spectra of FGP and GA are shown in Figure $1 \mathrm{~B}$ and display prominent peaks at 3317 (O-H stretch), 2905 (C-H stretch), 1603 (O-H bend, water), 1140 (C-O stretch), 1065 (C-O stretch), 1026 (C-O stretch), and 974 (C-O stretch) for each compound. The observed peaks in the FT-IR spectra are comparable with those found in the literature for GA. ${ }^{24,25}$ The similarities seen in the FT-IR spectra are consistent with the previous NMR structural analysis of FGP (Figure 2). ${ }^{5}$ Frost grape polysaccharide is an AG, in the same structural class as GA and guar gum but has several unique structural features that distinguish from other AG. A full mass spectrometric and NMR analysis of the frost grape polysaccharide has been published previously ${ }^{5}$ and show a conserved structural core of three $\alpha$-arabinofuranosyl branching residues (Araf 1, Araf 2, and Araf 3) and a $\beta$-galactosyl backbone residues (see Figure 2). By contrast, GA has a larger $\mathrm{Gal} / \mathrm{Ara}$ ratio and contains Rha residues that are not present for the FGP. There are also minor mannosyl and xylosyl monosaccharide components ( $7 \%$ and $5 \%$, respectively) in the FGP, plus a small amount $(2-3 \%)$ of terminal glucuronic acid residues that readily distinguish the FGP structure from that of other AG.

FGP is a relatively thermostable plant polysaccharide, experiencing significant mass loss due to heating beginning at 


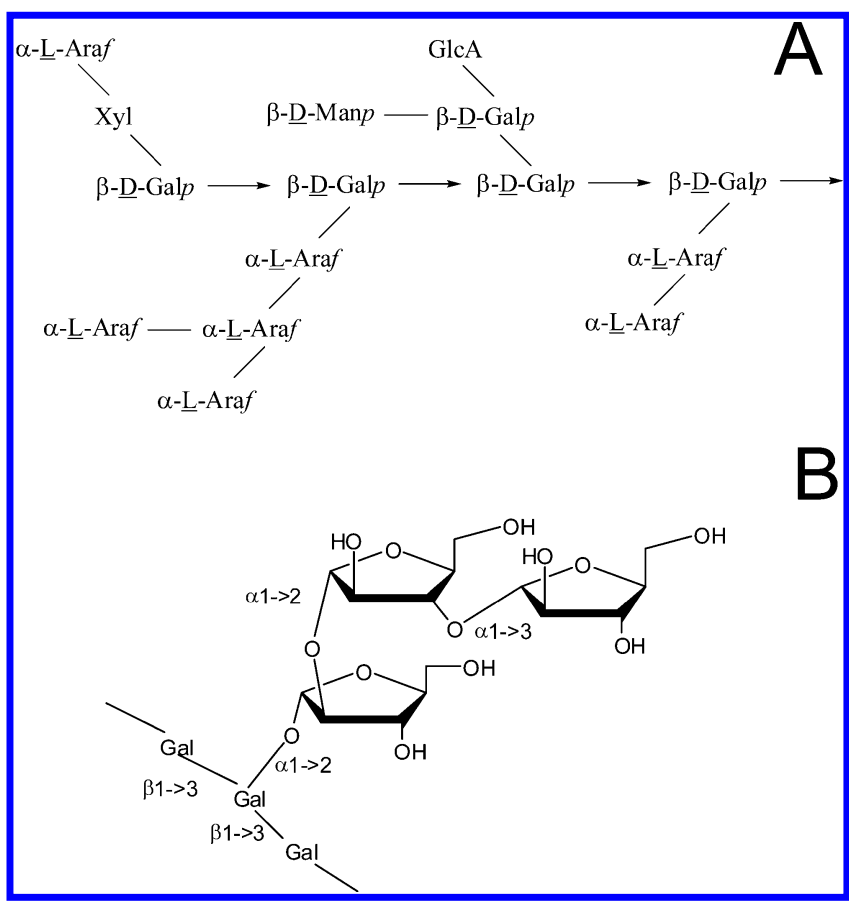

Figure 2. Proposed overall structure (A) and the detailed NMRdetermined triarabinosylgalactan motif (B) of the FGP. Based on the reference Price et al. ${ }^{5}$

approximately $238{ }^{\circ} \mathrm{C}$ with $50 \%$ mass loss occurring at $275{ }^{\circ} \mathrm{C}$ (Figure 3A). This is similar to that observed for Acacia gum. ${ }^{26}$ This thermostability may allow FGP to be used in a wide variety of food and industrial applications. FGP experiences an irreversible endothermic event at approximately $157^{\circ} \mathrm{C}$. This event occurs well below the onset of degradation by TGA and is not observed again when the same sample is cooled and reheated (Figure 3B). This indicates a nonmass loss structural change or reaction in FGP; such transitions have been seen in the DSC scans of Acacia gum. ${ }^{27}$

FGP is soluble in aqueous solutions at concentrations less than $2 \% \mathrm{w} / \mathrm{v}^{5}$ After solution preparation and centrifugation, no apparent insoluble material was present. FGP itself is a hygroscopic polysaccharide, reaching a moisture content of $38 \%$ at $90 \%$ relative humidity (Figure 4 ). FGP will readily

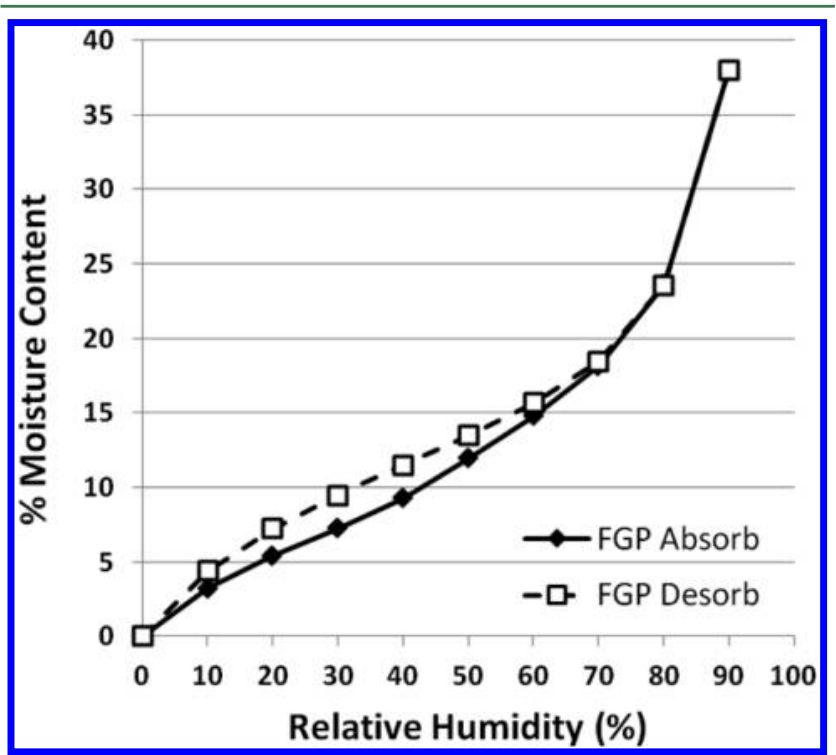

Figure 4. FGP atmospheric water absorption and desorption under varying relative humidity determined by TA Instruments' Q5000SA water vapor sorption analyzer.

absorb atmospheric water vapor but will more slowly desorb that moisture before equilibrating at $0 \%$ relative humidity. The hygroscopic nature of FGP is quite similar to that of GA, which reaches a moisture content of $37 \%$ at $90 \%$ relative humidity (data not shown). Proper storage and utilization of FGP for food and industrial applications must consider the relative humidity of the environment as FGP will readily absorb atmospheric water which may lead to storage issues and/or difficulty in processing.

3.2. Emulsion Functional Properties. The ability of FGP to act as a highly stable emulsifier was previously described in a qualitative experiment; ${ }^{5}$ however, it is essential for commercial adoption to determine a quantitative value. The Turbidimetric method was used for determining emulsion properties and was

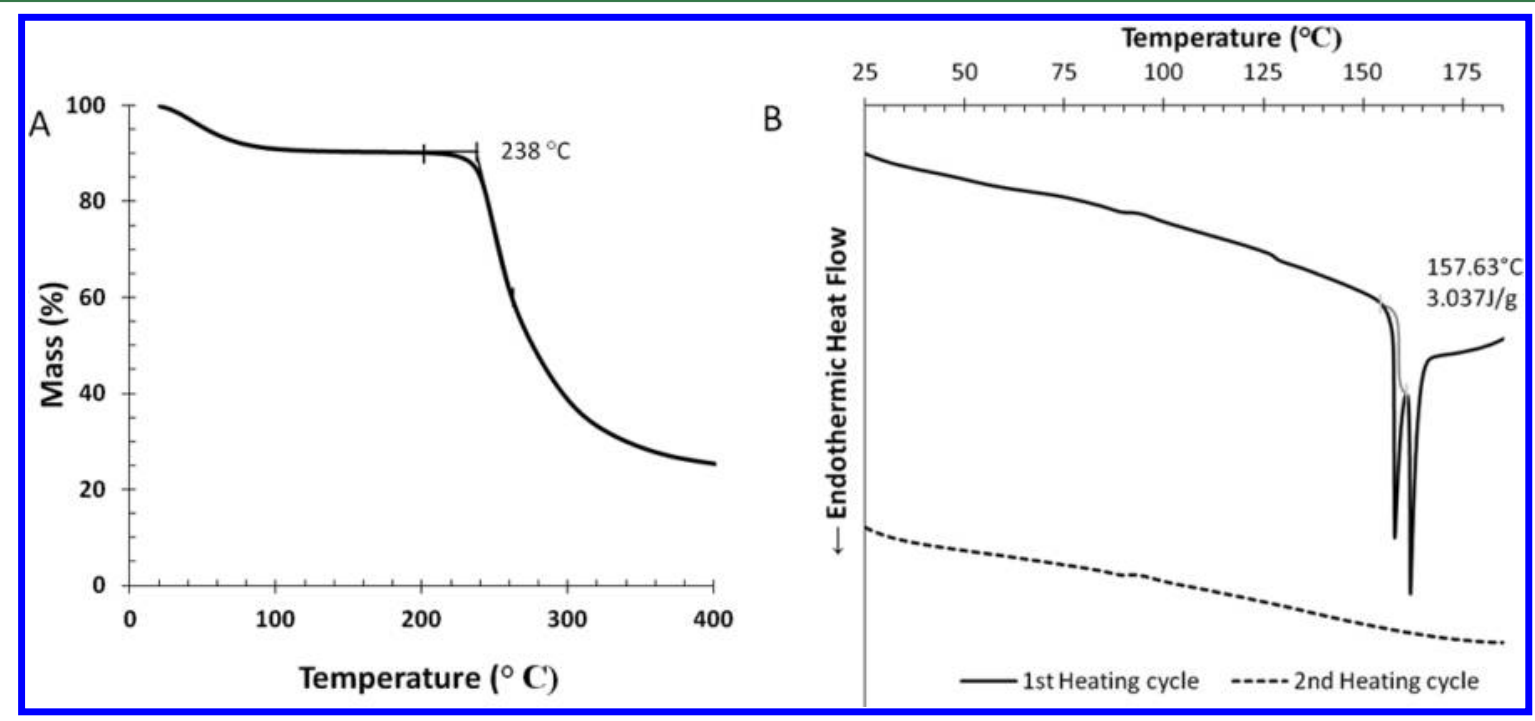

Figure 3. (A) TGA of the onset of degradation of FGP as determined by TA Instruments' Universal Analysis software. (B) Representative DSC of FGP at 10\% moisture content, using a Q2000 MDSC (TA Instruments, New Castle, DE). 
developed by Pearce and Kinsella ${ }^{28}$ and modified by Wu et al. ${ }^{23}$ This method was developed in part as a way to test and compare the emulsion performance of novel modifications or novel emulsifying agents. The emulsion characteristics are determined by the light scattering of dispersed spherical particles, oil droplets, in the aqueous continuous phase. This is due to the simple relationship between turbidity and the interfacial area of an emulsion. ${ }^{28}$ In stable emulsions the interfacial area does not change but as an emulsion breaks down there is an irreversible decrease in the interfacial area and thus absorbance decreases over time due to coalescence, flocculation, and gravitational separation. ${ }^{28,29}$ Flocculation would not impact the results due to the transfer of $50 \mu \mathrm{L}$ of the emulsified samples into $0.1 \%$ SDS, thus reversing any flocculation prior to testing the absorbance. It should also be noted that no gravitational separation, or creaming, was observed in the time frame of the tests for any of the samples; therefore, the change in absorbance as the emulsions broke down was only due to coalescence and oiling-off.

A $0.1 \%$ solids concentration was selected for the emulsifier tests to produce relatively low viscosity dilute oil in water emulsions and to assess the rate of emulsion breakdown. This resulted in oil in water emulsions with a 33:1 oil to emulsifier ratio. The EAI and $\mathrm{ESI}^{23,28}$ were determined for FGP and GA (Figure 5). FGP had a 35\% higher EAI than GA, i.e., FGP can

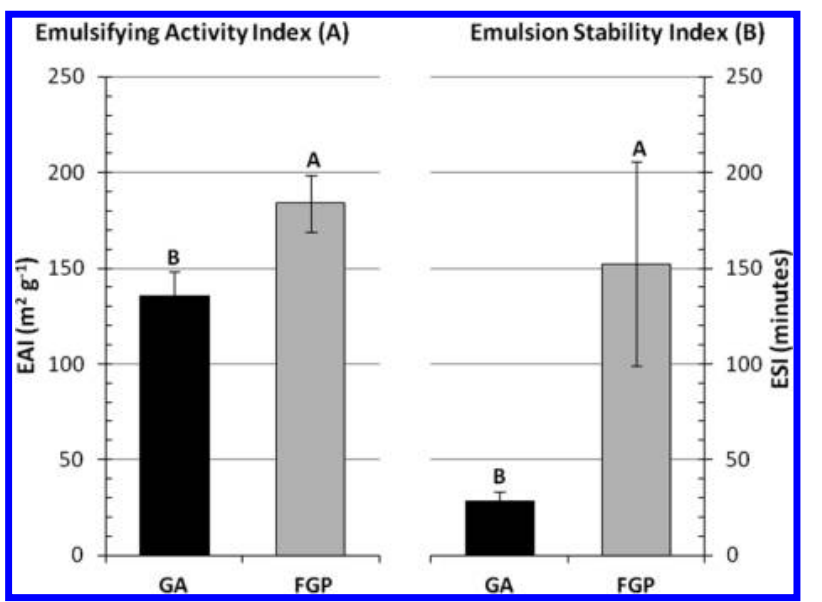

Figure 5. (A) EAI of GA and FGP. (B) ESI of GA and FGP.

emulsify a greater amount of oil than GA under the same conditions (Figure 5A). How FGP interacts with the oil phase is unknown because unlike GA, FGP lacks a hydroxyprolinerich protein and has little to no protein to interface with the oil phase. ${ }^{5}$ While a detailed mechanistic explanation of how FGP functions as an emulsifying agent is outside the scope of this manuscript, FGP may adopt a structural conformation which produces a hydrophobic region comprised of methylene groups and glycosidic linkages similar to what is observed in the helical formations of the carbohydrate scleroglucan. ${ }^{30}$

The nitrogen content (protein content) of GA generally correlates well with surface activity and is often a positive indicator of emulsion properties, but this relationship is not always clearly correlated with emulsion characteristics. ${ }^{14}$ GA samples with as little as $0.09 \% \mathrm{~N}$ contained enough proteinaceous fragments to produce stable emulsions, but commercial GA with a nitrogen content of approximately $0.3 \%$ displayed very little surface activity. ${ }^{9}$ An effective emulsifier rapidly reduces the interfacial tension at the oil-water interface by binding strongly to the interface to protect the droplets from flocculation and coalescence. ${ }^{12}$ The emulsifier will adhere to the interface, and the amphiphilic polymer orients its hydrophobic groups to the hydrophobic phase and hydrophilic groups to the aqueous phase. ${ }^{31}$ Surface tension decreases as the amount of absorbed polymer forming the interfacial film increases, thus providing steric repulsion and resistance to deformation. ${ }^{29,32}$ FGP displays surface activity with an average minimum surface tension of $60 \pm 2 \mathrm{dyn} / \mathrm{cm}$ for solutions with concentrations of $1-2 \%$ solids. The critical micelle concentration for FGP was determined to be $1 \%$ solids, with surface tension dramatically increasing at concentrations below $1 \%$ solids and finally being indistinguishable from water at $0.01 \%$ solids (data not shown). The nitrogen content analysis concluded that FGP contains $0.03 \pm 0.02 \%$ nitrogen, which corresponds to a range of roughly $0.04-0.3 \%$ protein $^{33-35}$ in the FGP isolate. The relatively high error was due to the low level of nitrogen present in the sample. It had been previously demonstrated that there was no observed hydroxyproline-rich protein association in FGP by using a colorimetric test for hydroxyproline and a Bradford assay. ${ }^{5}$ Therefore, we can conclude that there is no associated protein present in FGP, and what little residual protein, protein fragments, or minor constituents may cause the minimal surface activity observed in solutions of FGP. A high protein content is not necessarily an indicator of the emulsifying characteristics of a polysaccharide emulsifying agent and low protein content gums possessing excellent emulsifying characteristics have been observed for GA from $A$. Senegal and corn fiber gum. ${ }^{13,36,37}$

Consistent with previous literature observations FGP provides an exceptionally stable emulsion, with an emulsion stability index 6-10 times greater than that of GA at this usage level (0.1\%), i.e., FGP emulsions will remain stable for much longer than GA emulsions (Figure 5B). Emulsions undergo breakdown as they transition from a uniform dispersion to complete separation of phases. Oil droplets, which are less dense than the surrounding continuous phase (water + emulsifier), will undergo gravitational separation and rise through the emulsion column, a process largely dependent on the droplet size and the viscosity of the continuous phase. ${ }^{29}$ In the absence of agitation oil droplets can collide through Brownian motion and coalescence as the droplets combine to form one larger oil droplet. As the droplet diameter increases so does the rate of gravitational separation. This process can be inhibited by polymer adhesion at the interfacial surface, surface between the oil and water droplets. The polymers can form thick layers which provide steric stability by preventing oil droplet coalescence, with higher molecular weight polymers providing greater steric stability in slowing oil droplet coalescence. $^{13,38,39}$ This may explain the dramatic differences observed in the emulsion stability of FGP vs GA, as FGP has a 1-10 $\mathrm{MDa}^{5}$ molecular weight compared with GA:G9752 $2^{22}$ $(932 \mathrm{kDa})$. The intrinsic viscosity of FGP was determined to be $56.20 \mathrm{dL} / \mathrm{g}$ and is consistent with the previously reported molecular weight range of 1-10 MDa. The observed intrinsic viscosity of FGP is four times higher than that of guar gum using water as a solvent. ${ }^{40}$

The higher MW of FGP would provide superior steric inhibition of oil droplet coalescence. The molecular weight does not affect surface activity, but it is positively correlated with viscosity and emulsion stability parameters. ${ }^{38,41}$ The molecular weight of FGP is $1-10$ times larger than GA, ${ }^{2,42}$ and thus the dramatically increased stability observed in 

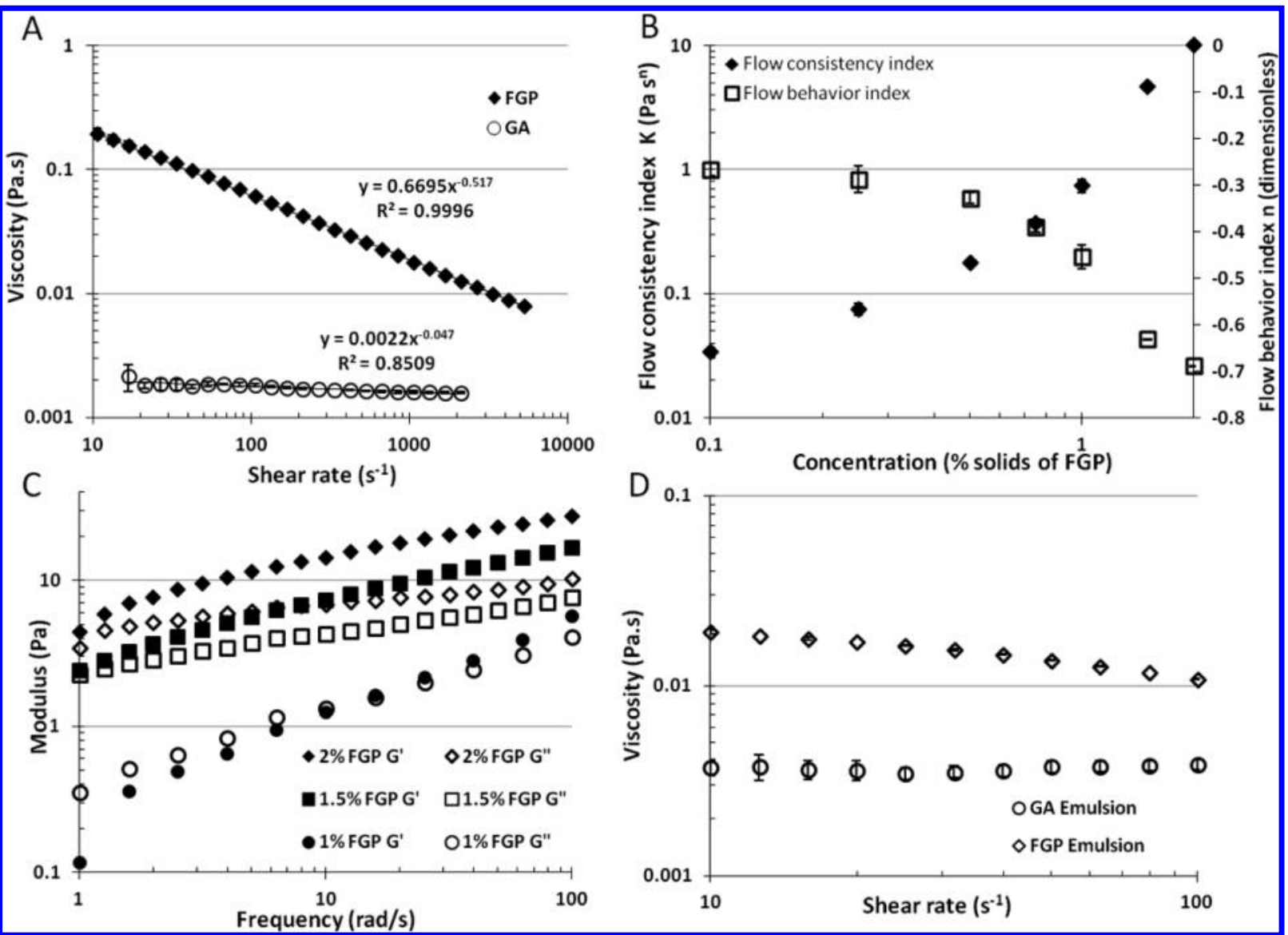

Figure 6. (A) Rheological properties of FGP and GA; shear thinning of a 1\% aqueous solution. (B) Power-law fluid relationship of FGP at varying solids concentration. (C) Small amplitude oscillatory shear flow measurements of 1, 1.5, and $2 \%$ solids concentration. (D) Shear thinning of fresh emulsions as prepared in section 2.9 .

emulsions formed from FGP are due in large part to this molecular weight difference. This impressive difference in emulsion stability would have tremendous value in reducing the necessary amount of emulsion stabilizers in a food product or producing food products which maintain stable emulsions for a longer length of time.

3.3. Rheological Properties of Solutions FGP. Controlled shear flow experiments were conducted on aqueous solutions containing 0.1 to $2 \%$ solids of FGP and $1 \%$ solids GA. The $1 \%$ solution of FGP displays a non-Newtonian shear thinning response, with decreasing viscosity in response to increasing shear rate (Figure 6A). Unlike FGP, GA displayed typical Newtonian behavior where the viscosity did not change with shear rate. The results for FGP followed the power-law model at all concentrations, $\eta(\dot{\gamma})=K \dot{\gamma}^{n-1}$, where $\eta$ is the viscosity, $\dot{\gamma}$ is the shear rate, $K$ is the consistency index, and $n$ is the flow behavior index. Solution differences observed in the shear thinning response is most likely due to the higher molecular weight of FGP compared with GA. As expected, solution viscosity increases with increasing concentration of FGP (Figure 6B), and the solutions became more strongly shear-thinning at higher concentration. Even at the lowest concentration of $0.1 \%$, FGP was shear-thinning and had a higher viscosity $(8.12 \pm 0.1 \mathrm{mPa} s)$ than a $1 \%$ solution of GA $(1.82 \pm 0.04 \mathrm{mPa} \mathrm{s})$ at $100 \mathrm{~s}^{-1}$. This is to be expected since the solution is well above the overlap concentration, which can be estimated as $1 /[\eta]^{43}$ or $0.002 \%$. The fresh emulsions formed from $0.1 \%$ FGP and oil, following the protocol in 2.9, also had a higher viscosity $(10.82 \pm 0.04 \mathrm{mPa} \mathrm{s})$ when compared with those made from $0.1 \% \mathrm{GA}$ and oil $(3.85 \pm 0.22 \mathrm{mPa} \mathrm{s})$ at 100 $\mathrm{s}^{-1}$ (Figure 6D) The high molecular weight FGP polymer adhering to the oil-water interface and the viscosity of the continuous phase would help explain the increased stability and reduced coalescence (Figure 5) observed in the FGP emulsions compared with GA emulsions.

The high solution viscosity would be valuable as a thickener for various applications. The linear viscoelastic properties of a $1 \%$ solution of FGP indicate the formation of a frequency dependent weak mechanical gel caused by physical entanglement, with a crossover point $\left(G^{\prime}>G^{\prime \prime}\right)$ at a frequency of 15.84 $\mathrm{rad} / \mathrm{s}$ (Figure 6C). Increasing the concentration of the solution to 1.5 and $2 \%$ solids resulted in the formation of mechanical gels with weak frequency dependence of the moduli, determined by $G^{\prime}$ being greater than $G^{\prime \prime}$ at all frequencies tested.

An irreversible structural change was observed in the DSC at high temperatures with no associated mass loss from the TGA analysis (Figure 3A,B). A change in the structure or conformation of FGP could significantly alter solution rheological properties, as observed in another polysaccharide used as an emulsion stabilizer, xanthan gum. If xanthan gum is heated beyond the transition temperature it will undergo a conformational change from a helix structure to a random coil, when cooled this can lead to a denatured structure. ${ }^{44-46}$ The ordered and denatured structures of xanthan show different side chain-backbone interactions and thus exhibit different 

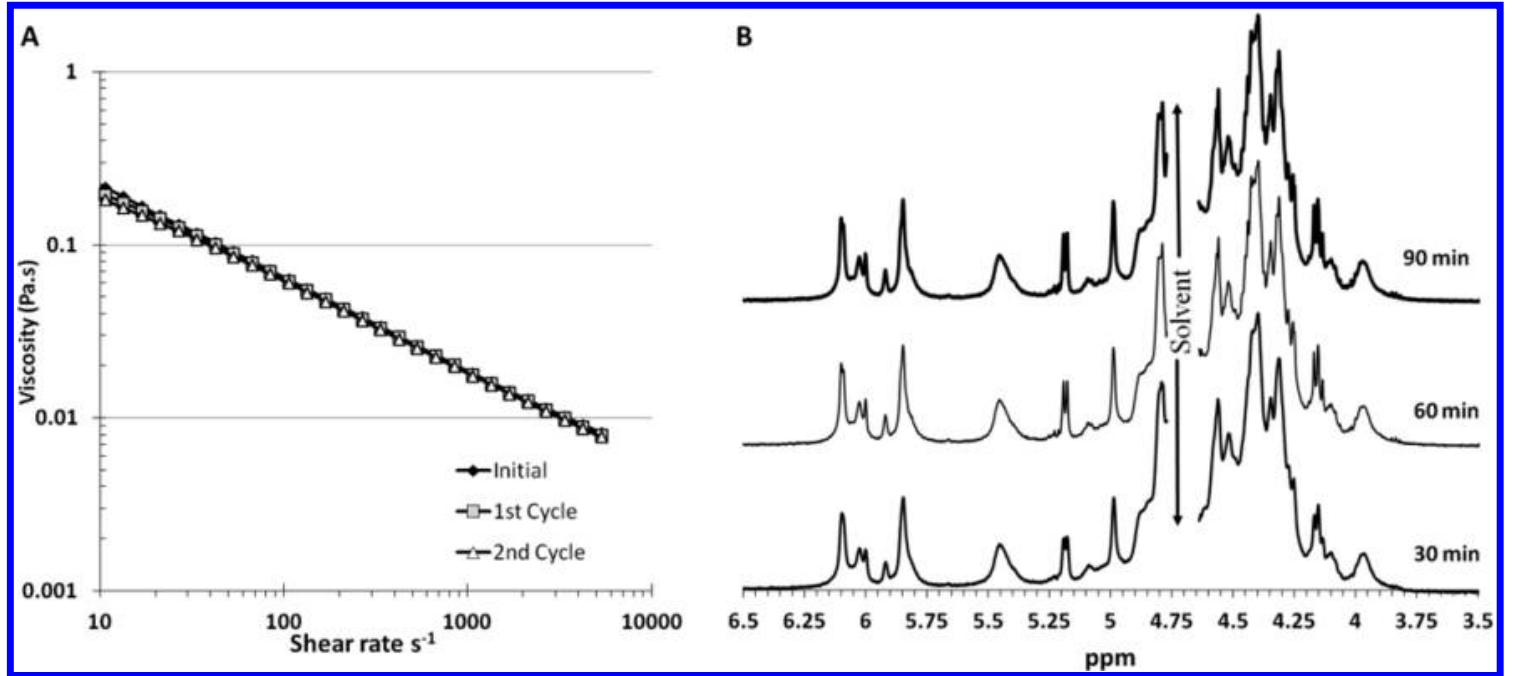

Figure 7. (A) $1 \%$ FGP solution viscosity after heating and cooling cycling from 20 to $90{ }^{\circ} \mathrm{C}$ to $20{ }^{\circ} \mathrm{C}$. (B) NMR spectroscopy of a $2 \%$ aqueous solution of FGP; NMR spectra of FGP heated and held at $90^{\circ} \mathrm{C}$, for 30,60 , and $90 \mathrm{~min}$.

Table 1. Mechanical Properties of FGP and GA Films ${ }^{a}$

$\begin{array}{ccccc}\text { sample } & \text { tensile strength }(\mathrm{MPa}) & \text { \% elongation } & \text { toughness }(\mathrm{MPa}) & \text { Young's modulus }(\mathrm{MPa}) \\ \text { GA } & 4.9 \pm 0.3 \mathrm{~B} & 77.6 \pm 7.3 \mathrm{~A} & 2.7 \pm 0.3 \mathrm{~B} & 24.9 \pm 9.5 \mathrm{~B} \\ \text { FGP } & 15.8 \pm 0.6 \mathrm{~A} & 60.2 \pm 15.4 \mathrm{~A} & 8.2 \pm 2.2 \mathrm{~A} & 178.6 \pm 13.6 \mathrm{~A}\end{array}$

${ }^{a}$ Letter groupings indicate statistically significant differences in the mechanical properties of FGP compared with GA in each column as determined by a Tukey adjusted LSD $\alpha<0.05$.

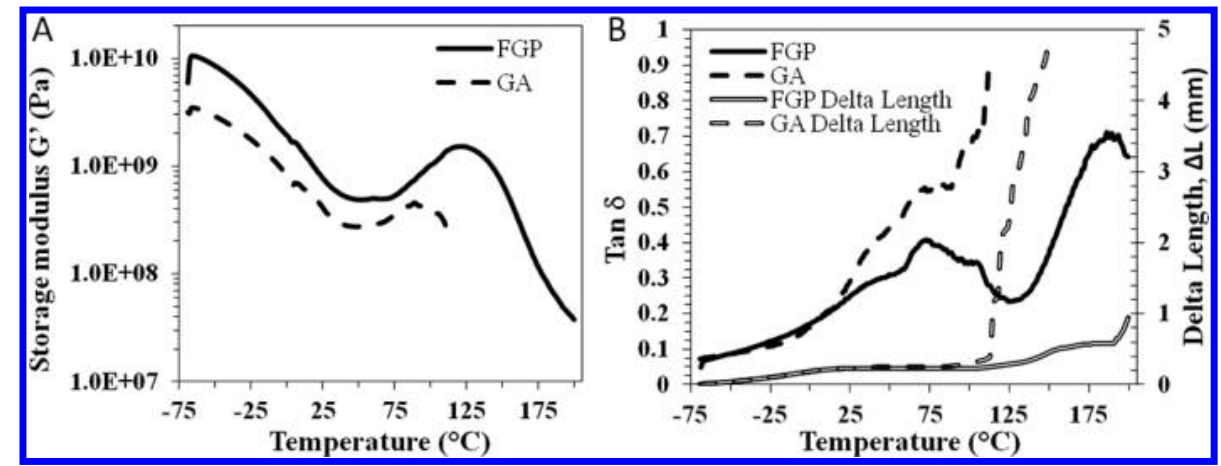

Figure 8. DMA of FGP and GA films with the addition of glycerol equal to $20 \%$ of the mass of the solids present in the solution: (A) $G^{\prime}$ of films vs temperature and (B) $\tan \delta$ and $(\Delta L)$ of films vs temperature.

viscosities in solution, but unless hydrolyzed will not change in molecular weight. $^{46}$ Xanthan gum will experience these conformational changes above $36{ }^{\circ} \mathrm{C}$ in aqueous solutions ${ }^{47}$ and the transition temperature increases with an increase in the salinity of the solution. ${ }^{44}$

To determine whether a conformational change in structure occurs in FGP with heating similar to xanthan gum, rheological characterization and NMR analysis were performed on thermocycled $1 \%$ solids aqueous solutions of FGP. There were no significant changes in the rheological characteristics of thermocycled FGP. The viscosity of FGP was found to be stable, with no change in viscosity after heating at $90{ }^{\circ} \mathrm{C}$ for up to $90 \mathrm{~min}$ (Figure 7A,B). Solutions of FGP experience a reversible viscosity loss in response to elevated temperature (Figure 7A). The solution viscosity remained stable even upon repeated temperature cycling $\left(20-90-20{ }^{\circ} \mathrm{C}\right)$ of the solution (Figure 7A). Aqueous solutions of FGP heated at $90{ }^{\circ} \mathrm{C}$ for 90 min underwent no structural changes as determined by NMR analysis of a $2 \%$ solution of FGP (Figure $7 \mathrm{~B}$ ). There was no detectable change $(<5 \%)$ in peaks and the peaks for FGP were comparable to those identified previously. ${ }^{5}$ From the reversible rheological thermocycling and NMR results, we can determine that FGP does not undergo a permanent structural conformational change upon heating up to $90{ }^{\circ} \mathrm{C}$.

3.4. Physical and Rheological Properties of FGP and GA Films. While FGP possesses outstanding emulsification properties, it is also an excellent film forming polymer, especially when compared with GA (Table 1). The ability to form a film may have value in food coating applications. A concentration of $20 \%$ glycerol was selected as a plasticizer for these films. This value was chosen as GA films were found to be very brittle and lower concentrations of glycerol resulted in poor quality films which could not be tested. FGP did not require glycerol to form testable films; however, to make comparisons with GA, only data from the films containing $20 \%$ glycerol will be reviewed. Films formed from FGP have significantly higher tensile strength, toughness, and Young's modulus than similar films formed from GA. Of significant 
interest is that films of FGP have three times the tensile strength of GA films with statistically equivalent \% elongation. Tensile strength is the force required to break the film, elongation is the amount the films will stretch until breakage occurs, toughness is the amount of energy a film can absorb before breakage, and Young's modulus (elastic modulus) is the stiffness of a film or its ability to resist deformation. These qualities are extremely important for any packaging or film application because these properties must be adequate to maintain film integrity during preparation, handling, or storage. $^{48}$ The excellent physical properties of FGP films is likely due in part to the higher molecular weight of the polysaccharide, similar to the effect of increasing molecular weight in pullulan films. ${ }^{49}$ Coatings and films of GA are used in the food and pharmaceutical industry, including in edible fruit coatings. ${ }^{18,50,51}$ This suggests that FGP could be used as a replacement to provide significant improvements to the final food article.

As previously described FGP has relatively high thermostability and determining the physical properties of films at elevated temperatures is an important aspect of defining industrial or commercial value. Mechanical characteristics were determined through DMA, performed on cast films of FGP and GA between -70 and $200{ }^{\circ} \mathrm{C}$ (Figure 8 ). The FGP cast films maintained a high storage modulus and remained intact even at a temperature as high as $200{ }^{\circ} \mathrm{C}$ (Figure $8 \mathrm{~A}$ ). The $G^{\prime}$ of FGP films decreased with increasing temperature until $75{ }^{\circ} \mathrm{C}$. After $75{ }^{\circ} \mathrm{C}$ the $G^{\prime}$ increased until $125^{\circ} \mathrm{C}$ where the $G^{\prime}$ continually dropped over an order of magnitude until the experiment completed at $200{ }^{\circ} \mathrm{C}$. Various transition temperatures can be determined by measuring how polymer properties vary with temperature while under an oscillatory strain. ${ }^{52}$ The GA cast films failed at temperatures exceeding $112{ }^{\circ} \mathrm{C}$, where the films exhibited extensive elongation $(5 \mathrm{~mm})$ indicative of film failure (Figure 8B). The FGP films have higher heat deflection temperatures, temperature of material deformation, compared to GA films. FGP had little change in length until $190{ }^{\circ} \mathrm{C}$ where the films extended approximately $1 \mathrm{~mm}$ (Figure $8 \mathrm{~B}$ ). The superior physical characteristics and heat deflection temperature of FGP films as compared with GA demonstrates additional value in industrial or food applications. Even with $20 \%$ glycerol as a plasticizer, the GA films remained brittle and many films failed during the preparation phase of the DMA analysis.

FGP is significantly superior to GA in a number of characteristics and could be an ideal replacement in many food applications to provide a superior food product. Compared with GA, FGP possesses greater emulsion activity and stability characteristics. Films of FGP have higher tensile strength, Young's Modulus, and a heat deflection temperature nearly $80{ }^{\circ} \mathrm{C}$ greater than GA. Protein allergies can be avoided since FGP has no associated protein component, unlike GA which is considered a potential sensitizer and an occupational allergen. GA appears to primarily cause asthma and rhinitis, though allergic symptoms have been observed after ingestion of products containing GA. ${ }^{53}$ The allergic reaction to GA is mediated preferentially by $\operatorname{IgE}$ antibodies directed to the polypeptide chains. ${ }^{54}$ Further study should be performed on the ability of FGP to maintain emulsion stability during longterm storage. Additionally, work is underway to identify whether other North American grape species produce the same or similar polysaccharides as that identified in Vitis riparia Michx.

\section{AUTHOR INFORMATION}

\section{Corresponding Author}

*E-mail: Neil.Price@ars.usda.gov.

ORCID

Neil P. J. Price: 0000-0001-6255-4357

\section{Notes}

Disclaimer: Mention of trade names or commercial products in this publication is solely for the purpose of providing specific information and does not imply recommendation or endorsement by the U.S. Department of Agriculture (USDA). USDA is an equal opportunity provider and employer.

The authors declare no competing financial interest.

\section{ACKNOWLEDGMENTS}

The assistance of A. J. Thomas with testing of rheological properties, Kelly Utt with acquiring the ATR FT-IR spectra, and Jason Adkins in determining water vapor sorption isotherms, differential scanning calorimetry, and thermal gravimetric analysis is gratefully acknowledged.

\section{REFERENCES}

(1) Free, D. L.; Krumel, K. L.; Snyder, T. C. Self-breaking viscous aqueous solutions and the use thereof in fracturing subterranean formations. U.S. Patent 3,960,736, June 1, 1976.

(2) Saeed, F.; Pasha, I.; Anjum, F. M.; Sultan, M. T. Arabinoxylans and arabinogalactans: a comprehensive treatise. Crit. Rev. Food Sci. Nutr. 2011, 51, 467-476.

(3) Thevenet, F. Acacia Gums: Stabilizers for Flavor Encapsulation. In Flavor Encapsulation; ACS Symposium Series, Vol. 370; American Chemical Society: Washington, DC, 1988.

(4) Dickinson, E. Hydrocolloids at interfaces and the influence on the properties of dispersed systems. Food Hvdrocolloids 2003, 17, 25-39.

(5) Price, N. P.; Vermillion, K. E.; Eller, F. J.; Vaughn, S. F. Frost grape polysaccharide (FGP), an emulsion-forming arabinogalactan gum from the stems of native North American grape species Vitis riparia Michx. I. Arric. Food Chem. 2015, 63, 7286-93.

(6) Powell, K. S.; Cooper, P. D.; Forneck, A. The biology, physiology and host-plant interactions of grape phylloxera Daktulosphaira vitifoliae. Adv. Insect Phvsiol. 2013, 45, 159-218.

(7) Griesser, M.; Lawo, N. C.; Crespo-Martinez, S.; SchoedlHummel, K.; Wieczorek, K.; Gorecka, M.; Liebner, F.; Zweckmair, T.; Pavese, N. S.; Kreil, D. Phylloxera (Daktulosphaira vitifoliae Fitch) alters the carbohydrate metabolism in root galls to allowing the compatible interaction with grapevine (Vitis ssp.) roots. Plant Sci. 2015, 234, 38-49.

(8) Connolly, S.; Fenyo, J.-C.; Vandevelde, M.-C. Effect of a proteinase on the macromolecular distribution of Acacia senegal gum. Carbohvdr. Polvm. 1988, 8, 23-32.

(9) Dickinson, E.; Murray, B. S.; Stainsby, G.; Anderson, D. M. Surface activity and emulsifying behaviour of some Acacia gums. Food Hvdrocolloids 1988, 2, 477-490.

(10) Buffo, R.; Reineccius, G.; Oehlert, G. Factors affecting the emulsifying and rheological properties of gum acacia in beverage emulsions. Food Hvdrocolloids 2001, 15, 53-66.

(11) McNamee, B. F.; O’Riorda, E. D.; O'Sullivan, M. Emulsification and microencapsulation properties of gum arabic. L. Agric. Food Chem. 1998, 46, 4551-4555.

(12) Dickinson, E. Hydrocolloids as emulsifiers and emulsion stabilizers. Food Hvdrocolloids 2009, 23, 1473-1482.

(13) Yadav, M. P.; Parris, N.; Johnston, D. B.; Hicks, K. B. Fractionation, characterization, and study of the emulsifying properties of corn fiber gum. L. Agric. Food Chem. 2008, 56, 4181-4187.

(14) Randall, R.; Phillips, G.; Williams, P. The role of the proteinaceous component on the emulsifying properties of gum arabic. Food Hudrocolloids 1988, 2, 131-140. 
(15) Dickinson, E. The role of hydrocolloids in stabilising particulate dispersions and emulsions. In Gums and Stabilisers for the Food Industry; Phillips, G. O., Wedlock, D. J., Williams, P.A, Eds.; IRL Press: Oxford, U.K., 1988; Vol. 4, pp 249-263.

(16) Tharanathan, R. Biodegradable films and composite coatings: past, present and future. Trends Food Sci. Technol. 2003, 14, 71-78.

(17) Verbeken, D.; Dierckx, S.; Dewettinck, K. Exudate gums: occurrence, production, and applications. Appl. Microbiol. Biotechnol. 2003, 63, 10-21.

(18) Ali, A.; Maqbool, M.; Ramachandran, S.; Alderson, P. G. Gum arabic as a novel edible coating for enhancing shelf-life and improving postharvest quality of tomato (Solanum lycopersicum L.) fruit. Postharvest Biol. Technol. 2010, 58, 42-47.

(19) Van Aken, G. A.; Vingerhoeds, M. H.; De Wijk, R. A. Textural perception of liquid emulsions: Role of oil content, oil viscosity and emulsion viscosity. Food Hvdrocolloids 2011, 25, 789-796.

(20) Baldwin, E. A.; Hagenmaier, R.; Bai, J. Edible Coatings and Films to Improve Food Quality; CRC Press: Baton Rouge, FL, 2011.

(21) Conforti, F. D.; Totty, J. A. Effect of three lipid/hydrocolloid coatings on shelf life stability of Golden Delicious apples. Int. I. Food Sci. Technol. 2007, 42, 1101-1106.

(22) Grein, A.; da Silva, B. C.; Wendel, C. F.; Tischer, C. A.; Sierakowski, M. R.; Moura, A. B. D.; Iacomini, M.; Gorin, P. A.; SimasTosin, F. F.; Riegel-Vidotti, I. C. Structural characterization and emulsifying properties of polysaccharides of Acacia mearnsii de Wild gum. Carbohvdr. Polvm. 2013, 92, 312-320.

(23) Wu, W.; Hettiarachchy, N.; Qi, M. Hydrophobicity, solubility, and emulsifying properties of soy protein peptides prepared by papain modification and ultrafiltration. I. Am. Oil Chem. Soc. 1998, 75, 845850.

(24) Reis, A. V.; Guilherme, M. R.; Cavalcanti, O. A.; Rubira, A. F.; Muniz, E. C. Synthesis and characterization of $\mathrm{pH}$-responsive hydrogels based on chemically modified Arabic gum polysaccharide. Polvmer 2006, 47, 2023-2029.

(25) Renard, D.; Lavenant-Gourgeon, L.; Ralet, M.-C.; Sanchez, C. Acacia $s$ enegal gum: Continuum of molecular species differing by their protein to sugar ratio, molecular weight, and charges. Biomacromolecules 2006, 7, 2637-2649.

(26) Daoub, R. M.; Elmubarak, A. H.; Misran, M.; Hassan, E. A.; Osman, M. E. Characterization and functional properties of some natural Acacia gums. J. Saudi Soc. Agric. Sci. 2016, DOI: 10.1016/ j.jssas.2016.05.002.

(27) Daoub, R. M. A. Rheology and Stability of Emulsions of Some Acacia Gums and Their Blends. Sudan University of Science and Technology, Khartoum, Sudan, 2016.

(28) Pearce, K. N.; Kinsella, J. E. Emulsifying properties of proteins: evaluation of a turbidimetric technique. I. Agric. Food Chem. 1978, 26, $716-723$.

(29) Hailing, P. J.; Walstra, P. Protein-stabilized foams and emulsions. Crit. Rev. Food Sci. Nutr. 1981, 15, 155-203.

(30) Yanaki, T.; Norisuye, T. Triple helix and random coil of scleroglucan in dilute solution. Polvm. I. 1983, 15, 389-396.

(31) Schick, M. Surface films of nonionic detergents-I. Surface tension study. I. Colloid Sci. 1962, 17, 801-813.

(32) Capek, I. Degradation of kinetically-stable o/w emulsions. Adv. Colloid Interface Sci. 2004, 107, 125-155.

(33) Maynard, L. A.; Loosli, J. K. Animal Nutrition; McGraw-Hill: New York, 1965.

(34) Milton, K.; Dintzis, F. R. Nitrogen-to-protein conversion factors for tropical plant samples. Biotropica 1981, 13, 177-181.

(35) Yeoh, H.-H.; Wee, Y.-C. Leaf protein contents and nitrogen-toprotein conversion factors for 90 plant species. Food Chem. 1994, 49, 245-250.

(36) Dickinson, E.; Galazka, V. B.; Anderson, D. M. Emulsifying behaviour of gum arabic. Part 2: Effect of the gum molecular weight on the emulsion droplet-size distribution. Carbohvdr. Polvm. 1991, 14, 385-392.

(37) Garti, N.; Reichman, D. Surface properties and emulsification activity of galactomannans. Food Hvdrocolloids 1994, 8, 155-173.
(38) Dickinson, E.; Galazka, V.; Anderson, D. Effect of the molecular weight on the emulsifying behavior of gum arabic. In Food Polvmers. Gel and Colloids; Dickinson, E., Ed.; Royal Society of Chemistry: Cambridge, U.K., 1991; pp 490-493.

(39) Aoki, H.; Katayama, T.; Ogasawara, T.; Sasaki, Y.; Al-Assaf, S.; Phillips, G. O. Characterization and properties of Acacia senegal (L.) Willd. var. Senegal with enhanced properties (Acacia (sen) SUPER GUM): Part 5. Factors affecting the emulsification of Acacia senegal and Acacia (sen) SUPER GUM. Food Hydrocolloids 2007, 21, 353358.

(40) Khouryieh, H.; Herald, T.; Aramouni, F.; Alavi, S. Intrinsic viscosity and viscoelastic properties of xanthan/guar mixtures in dilute solutions: Effect of salt concentration on the polymer interactions. Food Res. Int. 2007, 40, 883-893.

(41) Nakamura, M. Stabilization of emulsion by natural polymer. $I$. Iapan Oil Chem. Soc. 1986, 35, 554-560.

(42) Duvallet, S.; Fenyo, J.; Vandevelde, M. Meaning of molecular weight measurements of gum arabic. Polvmer Bull. 1989, 21, 517-521.

(43) Larson, R. G. The Structure and Rheology of Complex Fluids. Oxford University Press, New York, 1999; Vol. 150.

(44) Capron, I.; Brigand, G.; Muller, G. Thermal denaturation and renaturation of a fermentation broth of xanthan: rheological consequences. Int. J. Biol. Macromol. 1998, 23, 215-225.

(45) Naji, S.; Razavi, S. M.; Karazhiyan, H. Effect of thermal treatments on functional properties of cress seed (Lepidium sativum) and xanthan gums: A comparative study. Food Hydrocolloids 2012, 28, $75-81$.

(46) Milas, M.; Rinaudo, M. Properties of xanthan gum in aqueous solutions: Role of the conformational transition. Carbohydr. Res. 1986, 158, 191-204.

(47) Brunchi, C.-E.; Bercea, M.; Morariu, S.; Dascalu, M. Some properties of xanthan gum in aqueous solutions: effect of temperature and $\mathrm{pH}$. I. Polvm. Res. 2016, 23, 1-8.

(48) Wihodo, M.; Moraru, C. I. Physical and chemical methods used to enhance the structure and mechanical properties of protein films: A review. I. Food Eng. 2013, 114, 292-302.

(49) Lazaridou, A.; Biliaderis, C. G.; Kontogiorgos, V. Molecular weight effects on solution rheology of pullulan and mechanical properties of its films. Carbohvdr. Polvm. 2003, 52, 151-166.

(50) Maqbool, M.; Ali, A.; Alderson, P. G.; Zahid, N.; Siddiqui, Y. Effect of a novel edible composite coating based on gum arabic and chitosan on biochemical and physiological responses of banana fruits during cold storage. L. Agric. Food Chem. 2011, 59, 5474-5482.

(51) Lu, E.-X.; Jiang, Z.-Q.; Zhang, Q.-Z.; Jiang, X.-G. A waterinsoluble drug monolithic osmotic tablet system utilizing gum arabic as an osmotic, suspending and expanding agent. L. Controlled Release 2003, 92, 375-382.

(52) Duncan, J. Principles and applications of mechanical thermal analysis. In Principles and Applications of Thermal Analysis, 2nd ed.; Gabbott, P., Ed.; Blackwell: Oxford, U.K., 2008; pp 119-189.

(53) Viinanen, A.; Salokannel, M.; Lammintausta, K. Gum arabic as a cause of occupational allergy. I. Allergy 2011, 2011, 1.

(54) Sander, I.; Raulf-Heimsoth, M.; Wiemer, K.; Kespohl, S.; Bruening, T.; Merget, R. Sensitization due to gum arabic (Acacia senegal): the cause of occupational allergic asthma or crossreaction to carbohydrates? Int. Arch. Allergy Immunol. 2006, 141, 51-56. 